$$
\begin{aligned}
& \text { 震 }
\end{aligned}
$$

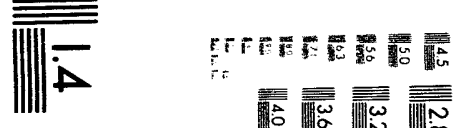

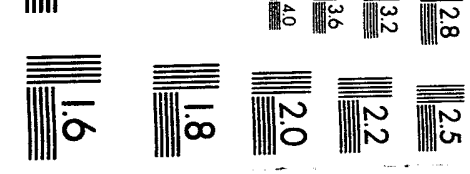



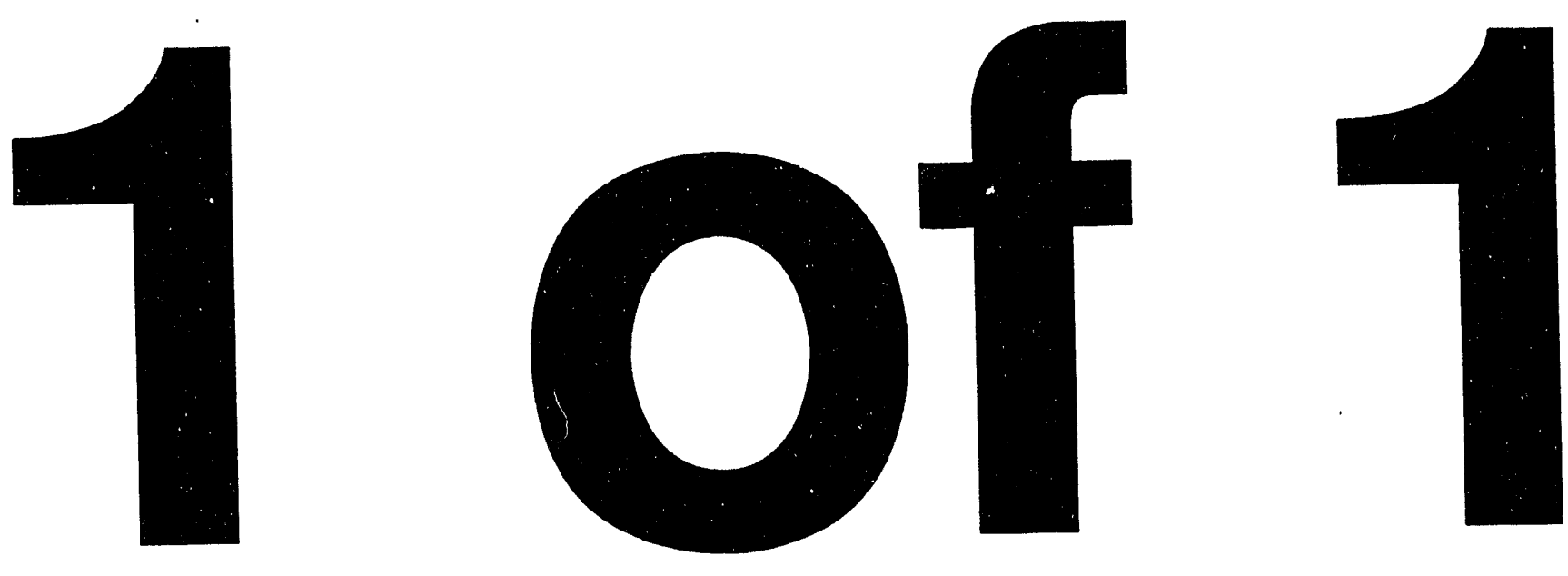


\title{
The Bridge Permeameter; An Alternative Method for Single-Phase, Steady-State Permeability Measurements
}

\author{
D. C. Graf, N. R. Warpinski
}

\begin{abstract}
An alternative method for measuring single-phase, steady-state permeability of porous rock is presented. The use of troublesome and expensive mass flow meters is eliminated and replaced with a bridge configuration of flow resistors. Permeability values can be determined directly from differential pressures across the bridge network, resulting in potentially significant cost savings and simplification for conducting these types of imeasurements. Results from the bridge permeameter are compared with results obtained using conventional methods.
\end{abstract}

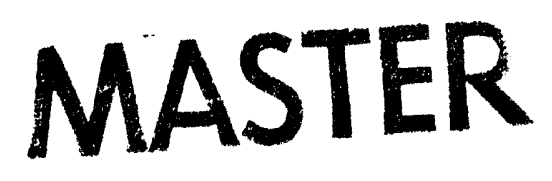




\section{TABLE OF CONTENTS}

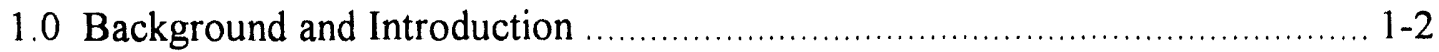

2.0 The Bridge Permeameter Method …......................................... 2-5

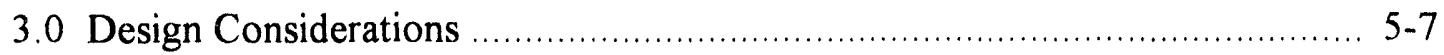

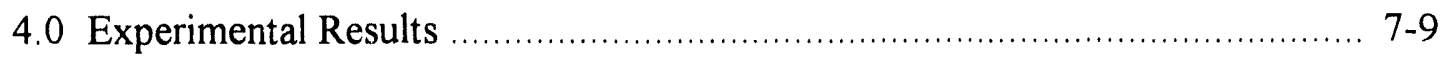

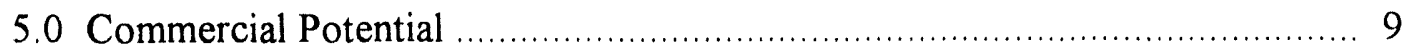

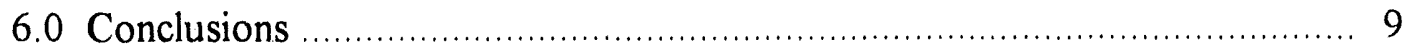

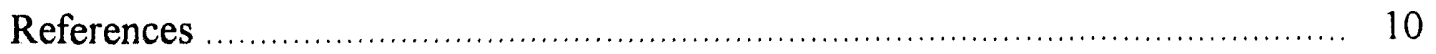

Appendix A: Flow Data and 3-Dimensional Models for the Flow Resistors ........ 11-14

FIGURES

1. Typical Permeability Configuration .......................................... 2

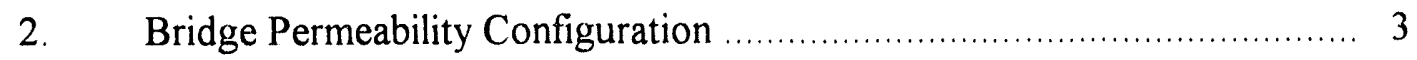

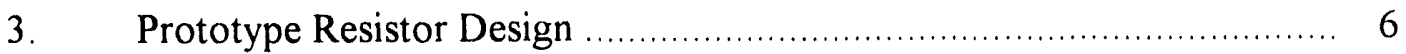

4. Comparison of Permeability Methods, $\Delta \mathrm{P}_{\mathrm{g}} \approx 90 \mathrm{psi} \ldots \ldots \ldots \ldots \ldots \ldots \ldots \ldots \ldots \ldots$

5. Comparison of Permeability Methods, $\Delta \mathrm{P}_{\mathrm{g}} \approx 180 \mathrm{psi} \ldots \ldots \ldots \ldots \ldots \ldots \ldots \ldots . \quad 8$

6. 3-Dimensional Curve-Fit Models for the Resistors ........................ 12-14 


\subsection{BACKGROUND AND INTRODUCTION}

Laboratory measurements of single-phase, steady-state permeability of porous rock are important for a number of different applications. The oil and gas industry uses permeability data as a key indicator of the producability of a hydrocarbon reservoir; effective containment of large volumes of oil in underground salt caverns is directly dependent upon the permeability of the adjacent cavern walls; and safe, long term underground isolation of radioactive and hazardous waste is contingent upon the flow and transport characteristics of the surrounding geologic formations.

Because of the importance of permeability characteristics in a number of different earth science fields, laboratory equipment for conducting these measurements commonly exists throughout private industry, universities, and government research organizations. There are two types of permeability tests that are typically performed today, -- the steady-state test and the pulse test. The steady-state test consists of measuring the flow rate and pressure drop across a rock sample under conditions of steady pressure. The pulse test is performed by subjecting a rock to an average pore pressure, opening a reservoir of known volume at a higher (or lower) pressure, and measuring the change in pressure as fluid flows into (or out of) the rock sample.

Steady-state techniques can be used for all rocks under all conditions, but it is difficult and time consuming especially for low permeability rocks because steady conditions must be achieved and the flow rate must be measured. The pulse technique, which requires no flow measurement, works well for higher permeability rocks where the permeability is insensitive to pressure and small pressure changes (between the reservoir and the initial pore pressure) can be used. However, for rocks that exhibit significant stress sensitivity (low-permeability and naturally fractured samples), the pulse technique may be less accurate because the permeability within the sample may be changing, and this is not accounted for by the analysis. Furthermore, there is a question of equilibration within the sample. As a result of these problems, there are many applications where steady-state measurements are preferred to pulse measurements.

The equipment for single-phase, steady-state measurements is typically arranged as shown in Figure 1, and includes a bank of mass flow meters, a differential pressure transducer, and a back pressure regulator valve. This arrangement uses an inert gas, such as nitrogen, for the fluid media pumped through the sample. Inert gas is a common and often necessary choice for the flow medium because it will not react with constituents of the rock sample and change the rock's flow properties. 


\section{INLET PQRE \\ PRESS. SUURCE}

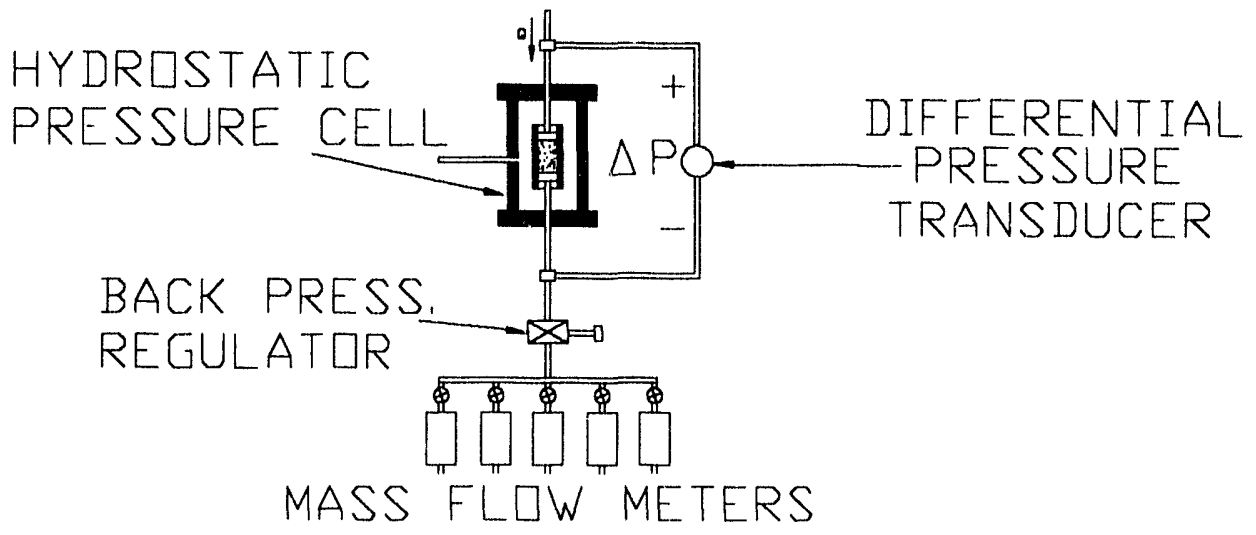

\section{FIGURE 1 - TYPICAL PERMEABILITY CONFIGURATION}

Difficulties arise with this arrangement because high differential pressures and low flow rates are required when testing lower permeability rocks. Flow rates tend to approach the lower limit of the commercially available flow meters, requiring that the driving pressure, or $\Delta \mathrm{p}$, be raised even higher so that a measurable level of flow can be maintained thrcugh the sample. However, this can also be problematic in that as the pressure gradient across the sample increases, the stress gradient within the sample increases, resulting in significant deviations from in situ conditions.

A second problem with this method concerns the associated costs involved with purchasing and maintaining the mass flow meters. To cover of the permeability ranges of interest, a typical permeameter incorporates three to five of these flow meters. These units cost $\$ 1500$ - $\$ 2000$ a piece. Also, such flow meters require frequent and expensive calibration to maintain reliable accuracy, adding a periodic cost to conducting the measurements. Finally, these frequent calibrations can lead to significant down time for the permeameter system, further impeding cost effective and timely results.

\subsection{THE BRIDGE PERMEAMETER METHOD}

A new technique is proposed where the single-phase, steady-state permeability of tight rock can be measured without the use of expensive and troublesome mass flow meters. A bridge configuration of flow resistors is applied, as shown in Figure 2, and the sample permeability is determined directly from differential pressure measurements across the bridge network. The measurement method is analogous to the Wheatstone Bridge (Holman, 1989) used to measure electrical resistivity changes in resistance-type strain gauges. 


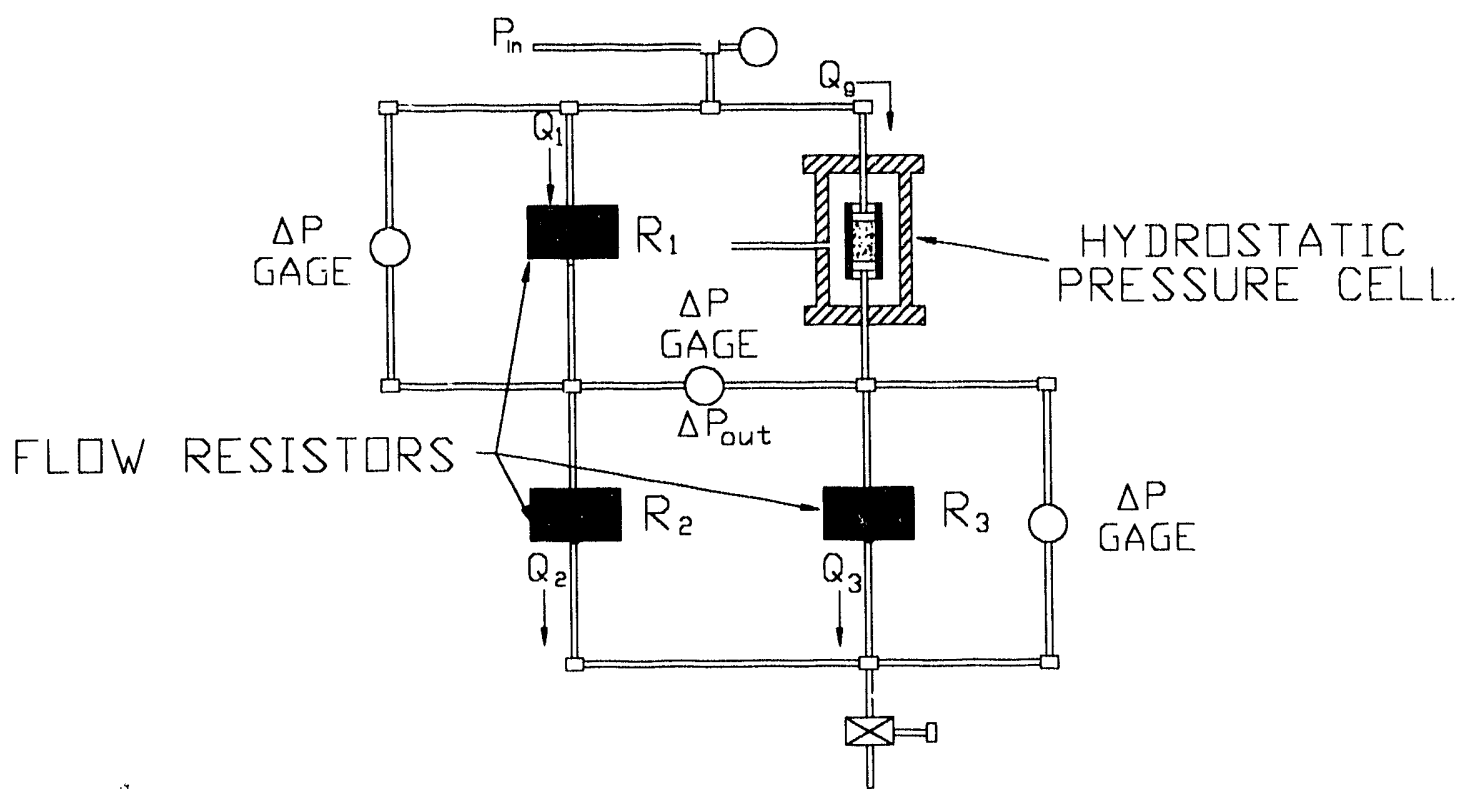

FIGURE 2 - BRIDGE PERMEAMETER CONFIGURATION

A derivation for a relatiunship between sample permeability, $\mathrm{k}_{\mathrm{S}}$, and differential bridge pressure, $\Delta \mathrm{p}_{\text {out }}$, closely parallels derivations for the electrical bridge networks. The concept incorporates summation of pressure rises and drops around the bridge, then solving for the unknown permeability of the sample in the hydrostatic pressure vessel.

Starting with Darcy's Law (API, 1956) for single-phase, steady-state, viscous flow through porous media,

$$
\Delta p=\frac{Q \mu L}{k \cdot A}
$$

where:

$\mathrm{k}_{\mathrm{S}}=$ sample permeability,

$\mu=$ fluid viscosity,

$\mathrm{Q}=$ flow rate,

$\mathrm{L}=$ sample length,

$\mathrm{A}=$ sample cross section,

$\Delta p=$ pressure drop across the sample.

A characteristic resistance, $R_{\mathrm{g}}$, can be given as

$$
R_{\mathrm{k}}=\frac{L}{k A}
$$


By substituting equation 2 into equation 1 ,

$$
\Delta p=Q \mu R_{8}
$$

Adding pressure rises and drops around the bridge we find that

$$
\Delta p_{\text {out }}=\Delta p_{3}-\Delta p_{2}
$$

where $\Delta p_{3}$ and $\Delta p_{2}$ are the pressure drops across $R_{3}$ and $R_{2}$, respectively, and $\Delta p_{\text {out }}$ is the pressure drop across the middle of the bridge. Substituting equation 3 into equation 4 yields

$$
\Delta p_{\text {out }}=Q_{3} \mu_{3} R_{3}-Q_{2} \mu_{2} R_{2}
$$

Because mass is conserved on each side of the bridge, we can see that $\mathrm{Q}_{1}=\mathrm{Q}_{2}$ and $\mathrm{Q}_{\mathrm{g}}=$ Q3. The flow rate through each side of the bridge is

$$
Q=\frac{\Delta p_{\text {in }}}{\mu_{a r} R_{\text {sum }}}
$$

where $R_{\text {sum }}$ is the sum of the two resistors on one side of the bridge, added in series. The average viscosity, $\mu_{\mathrm{av}}$, for the fluid flowing through each side of the bridge is taken as $\left(\mu_{\mathrm{x}}+\mu_{\mathrm{y}}\right) / 2$, where the subscripts $\mathrm{x}$ and $\mathrm{y}$ correspond to 1 and 2 for the left side of the bridge, and 3 and $g$ for the right side of the bridge. This assumes a linear relationship between viscosity and pressure, which for changes of gas pressure of less than a few hundred psi, introduces an insignificant error.

By substituting the general form of equation 6 for $Q_{3}$ and $Q_{2}$ into equation 5 and factoring out common terms, a relationship between differential bridge pressure and sample resistance, $R_{\mathrm{y}}$, is obtained such that

$$
\Delta p_{\text {out }}=\frac{\Delta p_{\text {in }}}{\mu_{\text {sav }}}\left[\frac{\mu_{3} R_{1}}{R_{3}+R_{8}}-\frac{\mu_{2} R_{2}}{R_{1}+R_{2}}\right]
$$

where:

$\Delta \mathrm{p}_{\text {out }}=$ pressure drop across the inner nodes of the bridge,

$\Delta \mathrm{p}_{\text {in }}=$ pressure drop across the entire bridge,

$\mathrm{R}_{1}=$ resistance 1 ,

$\mathrm{R}_{2}=$ resistance 2 ,

$\mathrm{R}_{3}=$ resistance 3 ,

$\mathrm{R}_{\mathrm{g}}=$ sample resistance,

$\mu_{\Delta \text { pav }}=$ viscosity at the average bridge pressure,

$\mu_{2}=$ viscosity at the average pressure at resistance 2 , and

$\mu_{3}=$ viscosity at the average pressure at resistance 3 . 
Noting that $R_{g}$ was defined in equation 2 , we can solve equation 7 for $R_{g}$ and substitute to get

$$
k_{s}=\frac{L}{A}\left[\left\{\left(\frac{\Delta p_{\text {ou }} \mu_{\text {sav }}}{\Delta p_{\text {in }}}+\frac{\mu_{2} R_{2}}{R_{1}+R_{2}}\right)^{-1} \mu_{3} R_{3}\right\}-R_{3}\right]^{-1}
$$

Equation 8 provides a direct relationship between sample permeability and differential bridge pressures given that $R_{1}, R_{2}$, and $R_{3}$ are known and $\mu_{\Delta p a v}, \mu_{2}, \mu_{3}$ can be calculated by knowing the average pressures at the indicated bridge points.

For compressible flow using inert gases, equation 8 is modified with a pressure ratio term as given in equation 9. This ratio is generally small, but can become large if the resistors are not sized properly for the application.

$$
k=\frac{L}{A}\left[\left\{\left(\frac{\Delta p_{\text {out }} \mu_{\text {spav }}}{\Delta p_{\text {in }}} \frac{P_{\text {out } a v}}{P_{\text {in } . a v}}+\frac{\mu_{2} R_{2}}{R_{1}+R_{2}}\right)^{-1} \mu_{3} R_{3}\right\}-R_{3}\right]^{-1}
$$

where: $\mathrm{P}_{\text {out, av }}$ and $\mathrm{P}_{\text {in, av }}$ are the average pore pressures at the $\Delta \mathrm{P}_{\text {out }}$ and $\Delta \mathrm{P}_{\text {in }}$ segments, respectively.

\subsection{DESIGN CONSIDERATIONS}

A key component to the functionality of the bridge permeameter is the flow resistor unit. These resistors could be other rock samples of known permeability, precision metering valves with known flow vs. pressure characteristics, or a small diameter orifice that can be characterized accurately for flow resistance. Of primary importance to any design is that the flow characteristics be highly repeatable and that the unit is not prohibitively costly. Another important consideration is that the unit be simple to set up, and that lengthy, repeated calibration procedures are avoided.

The primary focus of the development work carried out thus far has been the design and testing of these flow resistors. Figure 3 shows the prototype design of the resistors tested in the laboratory. 


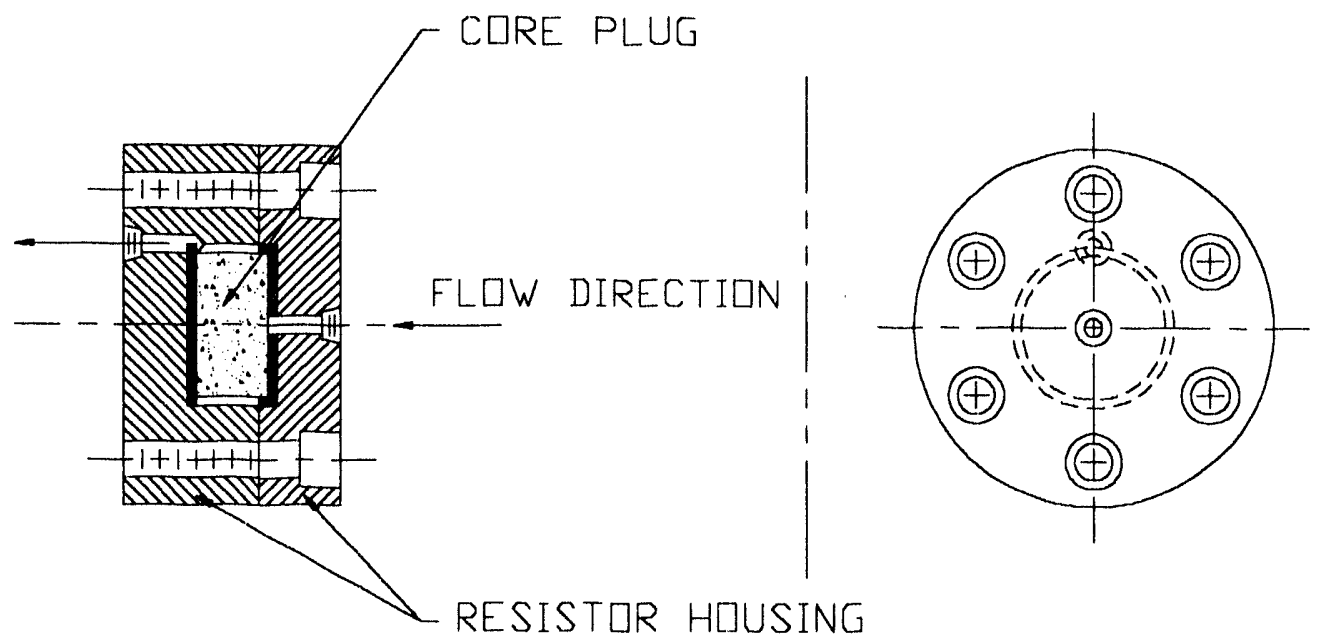

FIGURE 3 - PROTOTYPE RESISTOR FOR A BRIDGE PERMEAMETER

The intent of this particular design is to provide a simple and inexpensive means of flow resistance, one that can easily be reconfigured by merely changing the core plug. A 1.00 inch diameter by 0.5 inch long chalk sample was selected for the initial set of characterization tests, because of chalk's relative insensitivity of permeability to stress variations. This characteristic is important because the resistance, $L /(k \cdot A)$, must be relatively constant over a range of pore pressures so that resistors can more easily be matched with the expected permeabilities of the unknown sample.

A series of flow tests have been conducted on three different resistors of this design. The purpose of the tests was to characterize resistance, or $\mathrm{R}$ values, over a range of pore pressures and differential pressures. Once a matrix of data for each resistor was obtained, a 3-dimensional curve-fit model was applied to yield a relationship of

$$
k=a_{1}+a_{2} \cdot \Delta p+a_{3} \cdot p_{n}+a_{4} \cdot \Delta p^{2}+a_{n} \cdot \Delta p \cdot p_{r}+a_{n} \cdot p_{p}{ }^{2}
$$

where:

$\mathrm{k}=$ permeability at the given pressures,

$\Delta p=$ pressure drop across the resistor,

$\mathrm{p}_{\mathrm{p}}=$ average resistor pore pressure, and

$a_{1}, a_{2}, a_{3}, a_{4}, a_{5}$, and $a_{6}$ are known coefficients. 
Equation 10 can be solved for $k$, and substituted into equation 2 to provide resistance values for equation 9. Appendix A shows the resistance data, along with the 3-dimensional models for each resistor.

\subsection{EXPERIMENTAL RESULTS}

Using the 3-dimensional curve fit models developed for each resistor, a series of laboratory tests were then conducted to compare single-phase, steady-state permeability results from the bridge configuration to results obtained using conventional methods. Figures 4 and 5 show plots of permeability vs. pore pressure, at pressure drops across the sample of 90 psi and 180 psi, respectively.

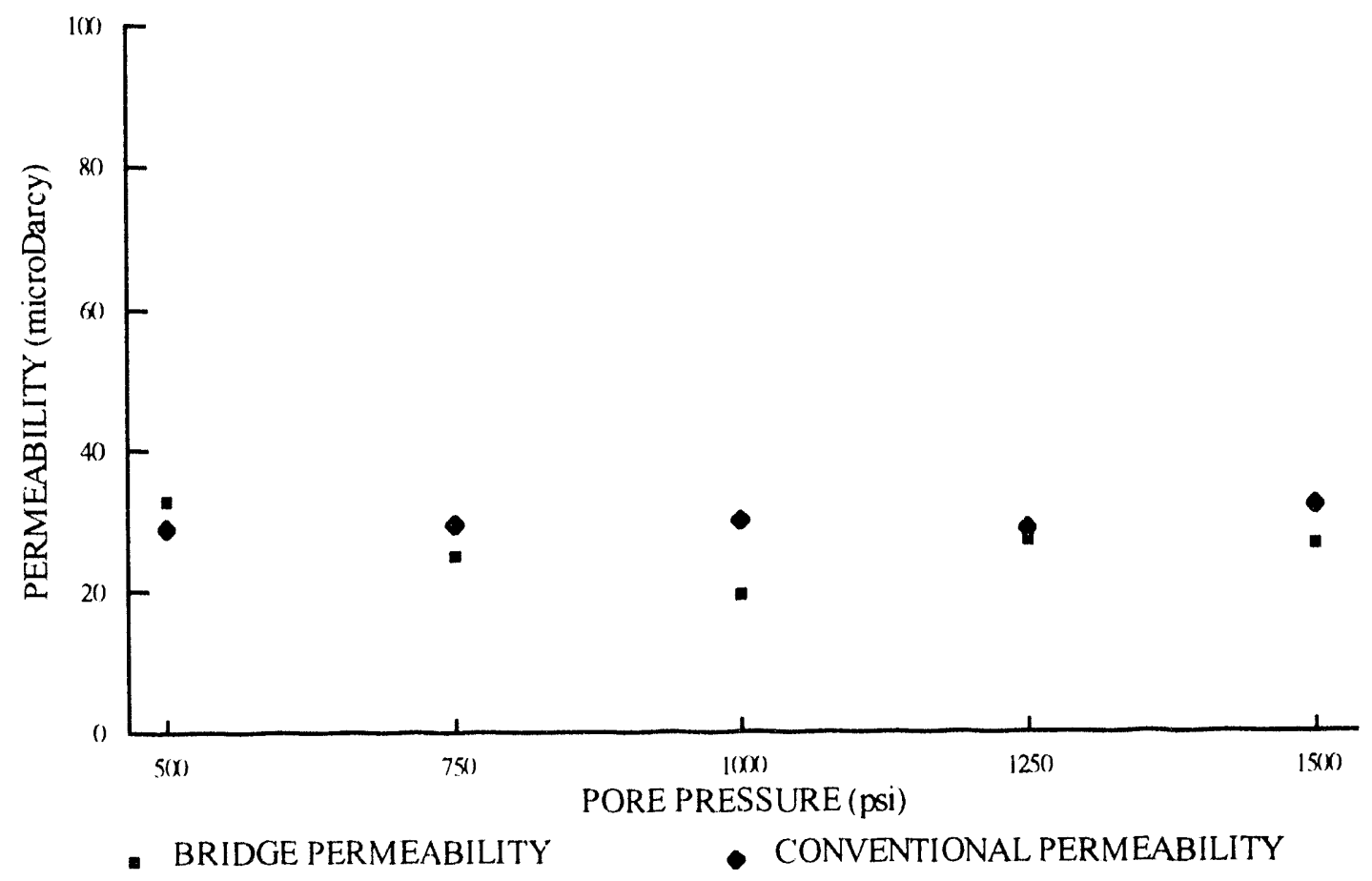

FIGURE 4 - COMPARISON OF PERMEABILITY METHODS, $\Delta \mathrm{P}_{\mathrm{g}} \approx 90 \mathrm{psi}$ 


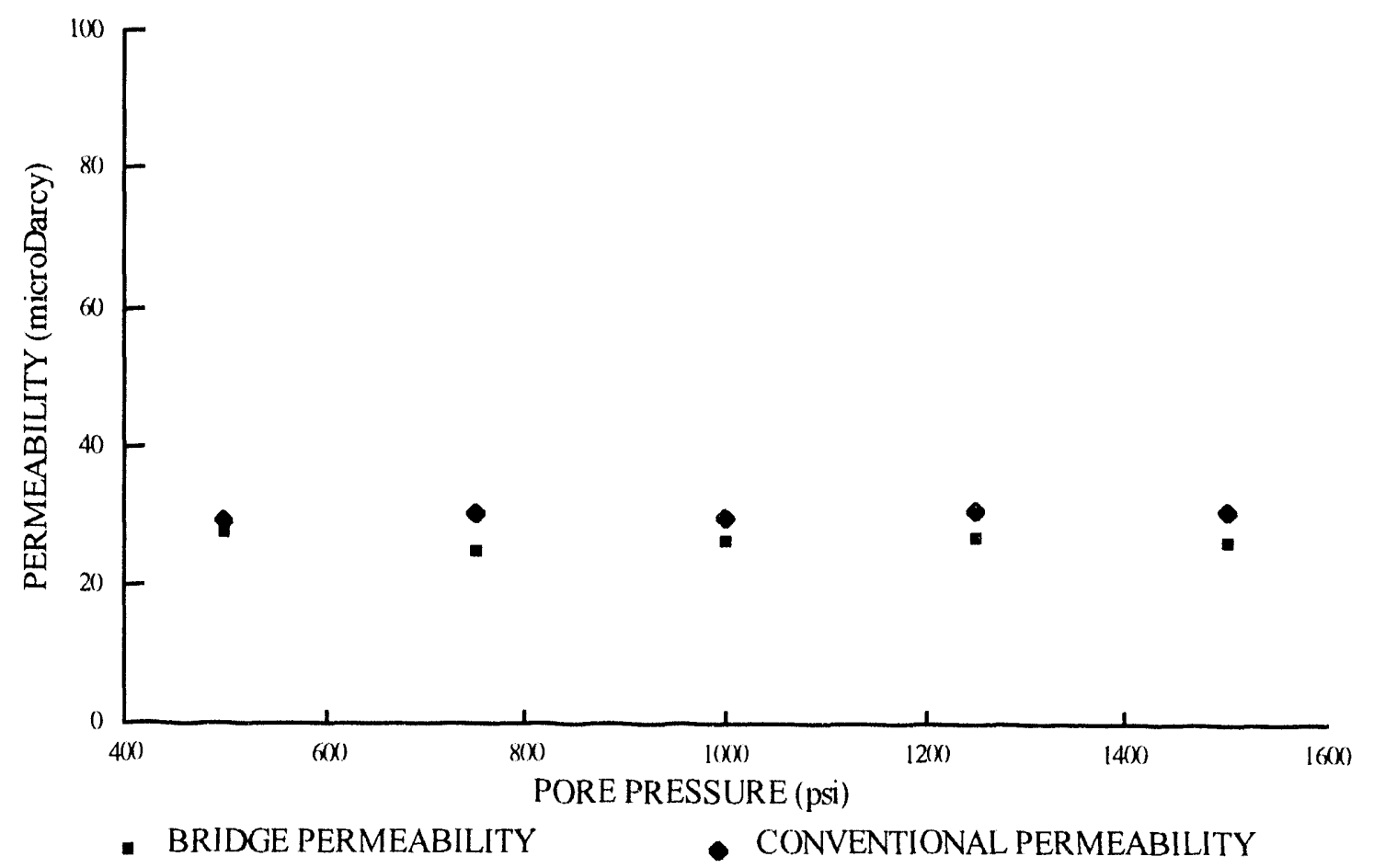

FIGURE 5 - COMPARISON OF PERMEABILITY METHODS, $\Delta \mathrm{P}_{\mathrm{g}} \approx 180 \mathrm{psi}$

The data show reasonably consistent agreement between the two methods, with the bridge permeameter results generally falling within $10-15 \%$ of conventional results. However, a number of problems emerged while conducting the laboratory tests. The mass flow meters used in conjunction with the tests displayed some disturbing inconsistencies. For example, while switching between flow meter 2 with a range of $0-50$ standard cubic centimeters per minute (SCCM) to flow meter 3 with a range $0-500$ SCCM, an inconsistency of 5-10 SCCM between the readings of the two instruments was experienced. Because of this inconsistency in the instrumentation, small errors are likely to exist in the curve-fit models for the resistors, and thus also in the permeability results obtained using those models. This equipment problem could easily account for a significant portion of the discrepancy between results from the two methods.

Another possible reason for the disparity between the two measurements is the presence of turbulent flow at the entrance to the resistor. A hollow disk configuration would enlarge the entrance area and minimize turbulence effects, but whole disks were used in these experiments to minimize machining and subsequent damage to the resistor rock specimens.

Regardless of the cause of the discrepancy, the comparison between the two techniques shows agreement that is quite good for permeability measurements (for low permeability rocks, a factor of two difference between different techniques is commonly observed). Furthermore, if this technique is to be used commercially, it is likely that new resistors with more constant properties could be developed. Some examples of possible materials include ceramics, cements, resin coated sand, fused silica and sintered metals. 


\subsection{COMMERCIAL POTENTIAL}

Because rock permeability is a key parameter in a number of different earth science applications, testing facilities using the conventional methods are prevalent throughout industry. Because of the prevalence of use and the previously stated costs and associated problems, the bridge permeameter device could offer a substantial cost savings and simplification in the equipment necessary to conduct these tests. As an example, consider that five flow meters at $\$ 1500$ per unit $(\$ 7500)$, plus one differential pressure transducer costing $\$ 800$ could be replaced with three clifferential pressure transducers $(\$ 2400)$ plus three flow resistors costing approximately $\$ 500$ per unit. The conventional equipment costs $\$ 8300$, while the bridge permeameter equipment costs only $\$ 3900$. Furthermore, depending on the frequency of calibration and type of flow meter used with the conventional method, an additional periodic cost savings could be realized using the bridge permeameter technique.

Given the widespread use of conventional measurement equipment and the estimated cost savings available with this new device, a significant commercial potential for this technology is likely to exist.

\subsection{CONCLUSIONS AND RECOMMENDATIONS}

Problems associated with flow meter accuracy and resistor model error must be addressed to facilitate a consistent, reliable bridge permeameter device. However, the laboratory tests conducted thus far on the bridge permeameter have provided a "proof of concept" basis for further investigations, and further development work concentrating on the plug resistor component and material characterization is recommended. Using the current resistor vessel design, a material such as ceramic or a potted cement could be developed that would have more predictable flow characteristics, eliminating the necessity of individual flow tests for each resistor.

If the development of this technique is to be continued, it would also be necessary to document the sensitivity of permeability to resistance. While the sensitivities can be easily obtained from derivatives of equations 8 and 9 , these sensitivities also require $\Delta p$, viscosity, and average pressure terms as well as the resistance terms. It is possible that two or three different sets of resistors would be required to cover a full range of permeabilities normally encountered.

Finally, developing a ceramic or other synthetic resistor for the bridge would require a teaming effort with material science experts. Sandia National Laboratories has this expertise available in a number of different Centers, and we recommend using this resource to facilitate advancement of a new and useful technology 


\section{REFERENCES}

(1) Holman, J. P., 1989, Experimental Methods for Engineers: pp. $114-117$ and 404 McGraw-Hill

(2) American Petroleum Institute, 1956, Recommended Practice for Determining Permeability of Porous Media: pp. 5- 7 


\section{APPENDIX A}

Laboratory Data and 3-Dimensional Curve-Fit Model for the Flow Resistors 
Resistor $\mathrm{R}_{1}$

\begin{tabular}{|r|r|r|r|}
\hline \multicolumn{1}{|c|}{ perm. ( $\mu$ Darcy) } & pore press. (psi) & resistance $\left(\mu\right.$ Darcy $\left.\mathbf{~}^{-1} \mathbf{c m}^{-1}\right)$ & diff. press. (psi) \\
\hline 36.4 & 2015.4 & 0.00688 & 9.5 \\
\hline 37.7 & 2011.9 & 0.00664 & 81.2 \\
\hline 38.2 & 2015.7 & 0.00656 & 96.8 \\
\hline 39.3 & 2013.3 & 0.00637 & 33.7 \\
\hline 37.6 & 1756.3 & 0.00666 & 10.7 \\
\hline 38.9 & 1765.7 & 0.00644 & 59.4 \\
\hline 39.6 & 1758.1 & 0.00632 & 100 \\
\hline 36.6 & 1508.5 & 0.00684 & 13.6 \\
\hline 40 & 1519.1 & 0.00626 & 60 \\
\hline 40.1 & 1514.2 & 0.00624 & 104.6 \\
\hline 37.1 & 1257.6 & 0.00675 & 12.6 \\
\hline 41.1 & 1255 & 0.00609 & 62.2 \\
\hline 40.9 & 1254.5 & 0.00612 & 113.6 \\
\hline 34.3 & 1002.4 & 0.00730 & 14.1 \\
\hline 40.9 & 1010 & 0.00612 & 70.2 \\
\hline 41 & 1011 & 0.00611 & 129.1 \\
\hline 35.2 & 748.7 & 0.00711 & 14.9 \\
\hline 41.5 & 755 & 0.00603 & 70.9 \\
\hline 42.1 & 763.3 & 0.00595 & 132.9 \\
\hline 35.9 & 500.1 & 0.00698 & 18.2 \\
\hline 43.1 & 501.8 & 0.00581 & 79.2 \\
\hline 43.5 & 503.7 & 0.00576 & 134.4 \\
\hline & & & \\
\hline
\end{tabular}

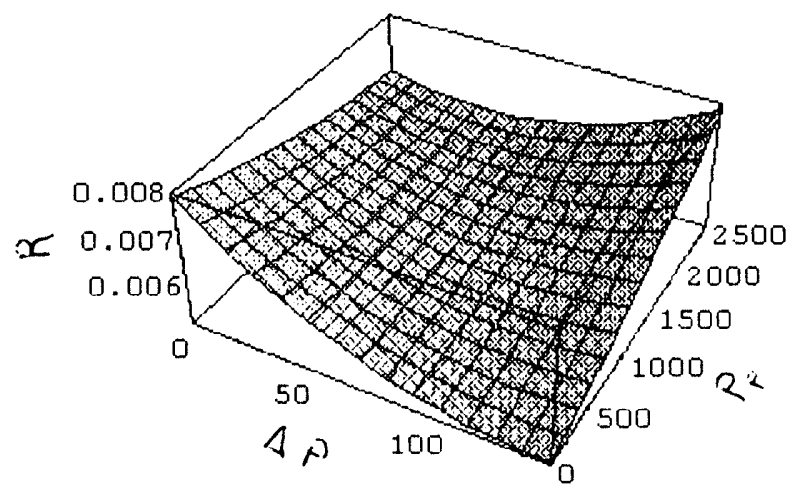

$$
\begin{gathered}
R_{1}=0.008051-\left(3.9811^{*} 10^{-4}\right) \Delta P+\left(1.4739^{*} 10^{-7}\right) \Delta P^{2}-\left(8.109^{*} 10^{-7}\right) P_{p}+ \\
\left(1.0919^{*} 10^{-8}\right) \Delta P^{*} P_{p}+\left(1.2801^{*} 10^{-10}\right) P_{p}{ }^{2}
\end{gathered}
$$

Figure A-1. 3-Dimensional Model of the Relationship Between Pore Pressure, Differential Pressure, and Resistance for Resistor $\mathrm{R}_{1}$. 
Resistor $\mathrm{R}_{2}$

\begin{tabular}{|c|c|c|c|}
\hline perm. ( $\mu$ Darcy) & pore press. (psi) & resistance $\left(\mu \operatorname{Darcy}^{-1} \mathrm{~cm}^{-1}\right)$ & diff. press. (psi) \\
\hline 50.8 & 2508.9 & 0.00493 & 10.4 \\
\hline 49.5 & 2517.5 & 0.00506 & 33.8 \\
\hline 48.7 & 2514.7 & 0.00514 & 58.6 \\
\hline 45.5 & 2519.3 & 0.00550 & 101 \\
\hline 50.6 & 2262.1 & 0.00495 & 11.2 \\
\hline 50.4 & 2260.5 & 0.00497 & 33.7 \\
\hline 49.4 & 2263.5 & 0.00507 & 66.8 \\
\hline 47.3 & 2262.7 & 0.00529 & 107.9 \\
\hline 49 & 2012.4 & 0.00511 & 11.7 \\
\hline 51 & 2009 & 0.00491 & 38.1 \\
\hline 49.1 & 2012.9 & 0.00510 & 75.7 \\
\hline 46.5 & 2016.4 & 0.00538 & 123.3 \\
\hline 49.8 & 1759.9 & 0.00503 & 11.7 \\
\hline 50 & 1764.1 & 0.00501 & 38.2 \\
\hline 48.8 & 1761 & 0.00513 & 85.1 \\
\hline 46.4 & 1759.5 & 0.00539 & 134.4 \\
\hline 48.5 & 1507.4 & 0.00516 & 13.3 \\
\hline 49.9 & 1500 & 0.00502 & 43 \\
\hline 48.3 & 1514.2 & 0.00518 & 98.9 \\
\hline 45 & 1512.1 & 0.00556 & 145.1 \\
\hline 49.9 & 1258.2 & 0.00502 & 13.2 \\
\hline 49.5 & 1257.9 & 0.00506 & 44.9 \\
\hline 48.9 & 1267.9 & 0.00512 & 80 \\
\hline 48.5 & 1255 & 0.00516 & 117.2 \\
\hline 51.2 & 1004.3 & 0.00489 & 13.4 \\
\hline 50.2 & 1004.6 & 0.00499 & 45.2 \\
\hline 49.1 & 1007.1 & 0.00510 & 93 \\
\hline 48.9 & 1002.6 & 0.00512 & 135.7 \\
\hline 51.1 & 753.5 & 0.00490 & 10.9 \\
\hline 50.2 & 761.6 & 0.00499 & 46.3 \\
\hline 50.3 & 748.2 & 0.00498 & 97.3 \\
\hline 46.7 & 748.2 & 0.00536 & 139.9 \\
\hline 52.8 & 502.2 & 0.00474 & 12.1 \\
\hline 50 & 510 & 0.00501 & 53.7 \\
\hline 50.9 & 496.4 & 0.00492 & 100.8 \\
\hline
\end{tabular}

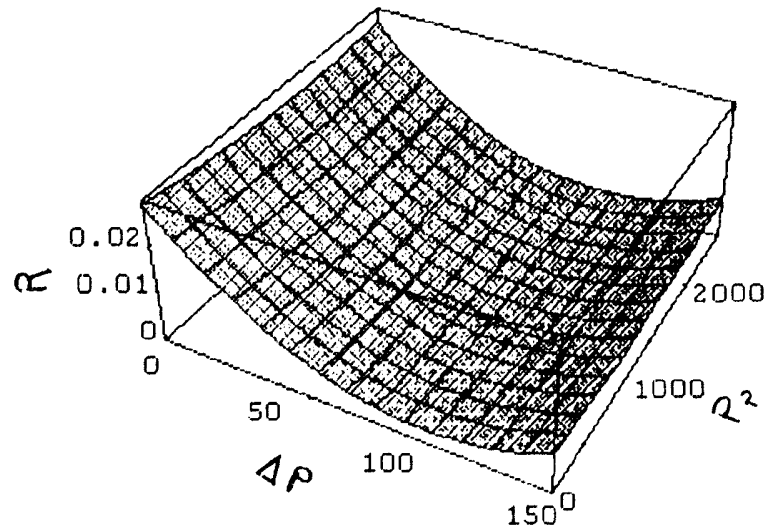

$$
\begin{gathered}
R_{2}=0.02797-\left(5.0754^{*} 10^{-4}\right) \Delta P+\left(2.4662^{*} 10^{-6}\right) \Delta P^{2}-\left(3.7423^{*} 10^{-6}\right) P_{p}+ \\
\left(7.8392^{*} 10^{-9}\right) \Delta P^{*} P_{p}+\left(1.0824^{*} 10^{-9}\right) P_{p} 2
\end{gathered}
$$

Figure A-2. 3-Dimensional Model of the Relationship Between Pore Pressure, Differential Pressure, and Resistance for Resistor $\mathrm{R}_{2}$. 
Resistor $\mathrm{R}_{3}$

\begin{tabular}{|c|c|c|c|}
\hline perm. ( $\mu$ Darcy) & pore press. (psi) & istance $\left(\mu\right.$ Darcy $\left.{ }^{-1} \mathrm{~cm}^{-1}\right)$ & diff. press. (psi) \\
\hline 53.7 & 2516.8 & 0.00466 & 12.4 \\
\hline 52.5 & 2521 & 0.00477 & 28.7 \\
\hline 49.2 & 2513.4 & 0.00509 & 62.9 \\
\hline 59.8 & 2506.8 & 0.00418 & 125.2 \\
\hline 54.4 & 2023.8 & 0.00460 & 13 \\
\hline 53.8 & 2010.8 & 0.00465 & 31.9 \\
\hline 49.7 & 2012.9 & 0.00504 & 73.8 \\
\hline 53.9 & 2004.4 & 0.00464 & 125.9 \\
\hline 54.7 & 1504.6 & 0.00457 & 17.2 \\
\hline 52.9 & 1517.6 & 0.00473 & 41.6 \\
\hline 51.8 & 1508.2 & 0.00483 & 79.6 \\
\hline 56.4 & 1505.4 & 0.00444 & 113.1 \\
\hline 52.1 & 1007.8 & 0.00480 & 14.4 \\
\hline 56.2 & 1008.9 & 0.00445 & 36 \\
\hline 54.1 & 1003.1 & 0.00463 & 77.4 \\
\hline 51.1 & 1010 & 0.00490 & 130.8 \\
\hline 53.6 & 498.9 & 0.00467 & 20.9 \\
\hline 63.6 & 503.9 & 0.00393 & 49.4 \\
\hline 63.9 & 503.9 & 0.00392 & 74.6 \\
\hline 64.1 & 495.7 & 0.00390 & 105 \\
\hline
\end{tabular}

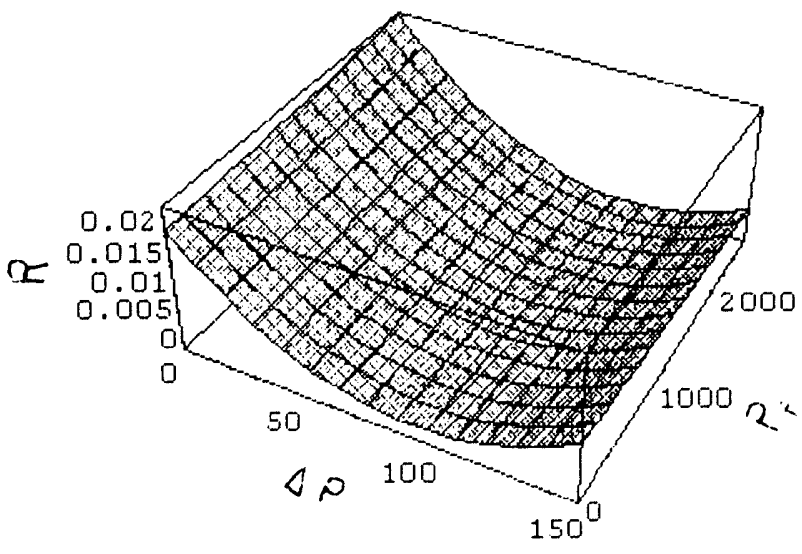

$R_{3}=0.019698-\left(3.9471 * 10^{-4}\right) \Delta P+\left(2.1746^{*} 10^{-6}\right) \Delta P 2+\left(1.1539 * 10^{-6}\right) P_{p}-$ $\left(1.8786^{*} 10^{-8}\right) \Delta P^{*} P_{p}+\left(4.9429^{*} 10^{-11}\right) P_{p} 2$

Figure A-3. 3-Dimensional Model of the Relationship Between Pore Pressure, Differential Pressure, and Resistance for Resistor $\mathrm{R}_{3}$. 


$\begin{array}{lll}\text { Internal Distribution: } & \\ \text { MS } & \text { Org. } & \\ 0701 & 6100 & \text { R. W. Lynch } \\ 0701 & 6101 & \text { E. D. Gorham } \\ 0706 & 6112 & \text { D. A. Northrop } \\ 0705 & 6114 & \text { M. W. Scott } \\ 0705 & 6114 & \text { N. R. Warpinski (5) } \\ 1324 & 6115 & \text { D. C. Graf (10) } \\ 1324 & 6115 & \text { Staff (10) } \\ 0750 & 6116 & \text { M. C. Walck (2) } \\ 0751 & 6117 & \text { S. R. Brown } \\ 0751 & 6117 & \text { L. W. Carlson } \\ 0751 & 6117 & \text { J. T. Fredrich } \\ 0751 & 6117 & \text { J. C. Lorenz } \\ 0751 & 6117 & \text { K. Morin } \\ 0751 & 6117 & \text { L. W. Teufel } \\ 0751 & 6117 & \text { D. H. Zeuch } \\ 1320 & 6119 & \text { F. Gelbard } \\ 9018 & 8523-2 & \text { Central Technical Files } \\ 0899 & 7141 & \text { Technical Library (5) } \\ 0619 & 7151 & \text { Technical Publications } \\ 0100 & 7613-2 & \text { Document Processing for DOE/OSTI (10) } \\ & 11510 & \text { M. Moss (3) } \\ & & \end{array}$



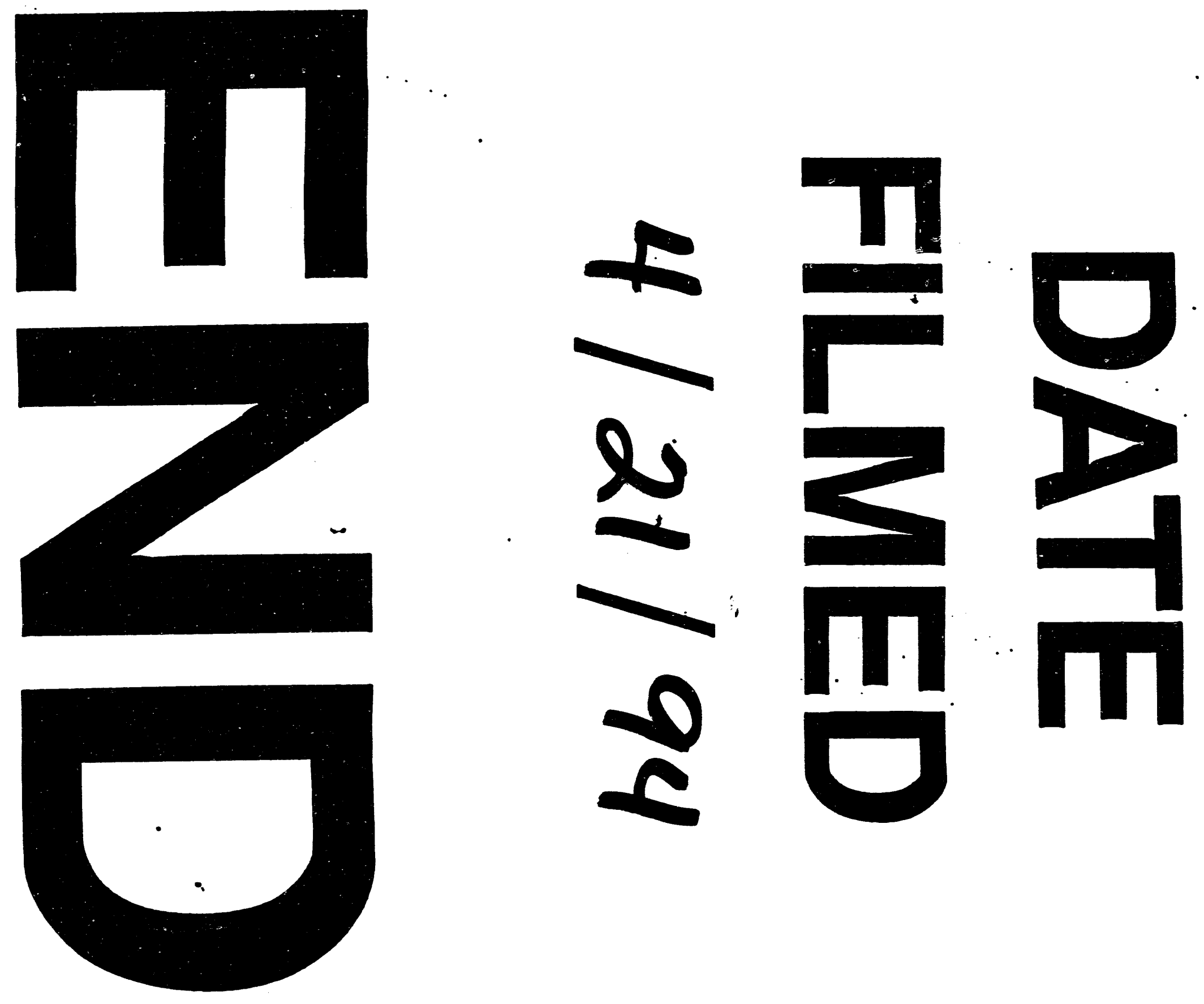
